\title{
V11 Vacina febre amarela de subunidade em plataforma vegetal: imunogenicidade e proteção de camundongos contra desafio letal
}

Rosane Cuber Guimarães ${ }^{1}$, Andrea Nazare Monteiro Rangel ${ }^{1}$, Marisol Simões ${ }^{1}$, Luciane Pinto Gaspar ${ }^{1}$, Elena Caride ${ }^{1}$, Marcos da Silva Freire ${ }^{1}$

${ }^{1}$ Bio-Manguinhos, Fiocruz, RJ

Introdução: A febre amarela é uma febre hemorrágica viral com cerca de 200.000 casos anuais estimados no mundo, e 30.000 mortes por ano. É também uma ameaça a milhões de pessoas que vivem e viajam para as áreas endêmicas. A atual vacina contra febre amarela, uma vacina de vírus vivo atenuado, vem provando ser a melhor maneira de se prevenir a doença e tem sido usada desde 1937, com notável eficácia. Todavia, desde 2001, raros eventos adversos agudos, mas graves, semelhantes aos da febre amarela silvestre e com alta letalidade, têm sido relatados. Reconhecendo o fato de que uma nova vacina segura deveria ser desenvolvida, Bio-Manguinhos e Fraunhofer têm focado na geração de vacinas de subunidades, utilizando a proteína do envelope $(\mathrm{E})$ do vírus da Febre Amarela. Este antígeno foi escolhido como alvo para o desenvolvimento de uma vacina de subunidade, utilizando a plataforma de expressão transiente em Nicotiana benthamiana (tabaco). Nestes estudos de desafio em camundongos foram investigadas a resposta humoral e a taxa de sobrevivência para três formulações do antígeno YFE com diferentes excipientes e adjuvantes.

Objetivo: Avaliar a resposta imunológica e a taxa de sobrevivência de camundongos após a inoculação de três diferentes alvos do antígeno YFE.

Metodologia: Todos os alvos foram produzidos pela Fraunhofer utilizando a plataforma de expressão transiente em plantas. O nível de purificação foi de $>95 \%$ para as proteínas solúveis e $>80 \%$ para a VLP. Para o estudo de desafio foram utilizados camundongos C57BL6 com 4 semanas de idade. O esquema vacinal foi estabelecido para os dias 0 , 14 e 28, com coletas de sangue para PRNT sempre dois dias antes da aplicação dos antígenos.

Resultados: Foram realizados 4 estudos de desafio letal em camundongos e em dois deles obtivemos uma taxa de sobrevivência de $100 \%$ do camundongos após o desafio letal, utilizando os antígenos YFE-1T (proteína solúvel) e YFE-(AL)3 (VLP).

Conclusão: Observou-se que as formulações que mostraram uma melhor eficácia e / ou títulos de anticorpos neutralizantes foram YFE$1 \mathrm{~T}+$ AbISCO $5 \mu \mathrm{g}$, duas doses, intramuscular; YFE- (AL) $3+$ AbISCO $5 \mu \mathrm{g}$, duas doses, intramuscular e YFE-2E + AbISCO $5 \mu \mathrm{g}$, duas doses, intramuscular. Apesar de todas as formulações terem a capacidade 
para induzir lgG YFE -específico (dados não mostrados) e títulos de anticorpos neutralizantes, não foi possível correlacionar o nível de resposta de anticorpos, com proteção. Correlatos de proteção induzidos por vacinação com uma vacina de subunidade contra a febre amarela deverão ser estabelecidos no futuro. Os resultados sugerem que a imunidade celular desempenha um papel fundamental na proteção contra a febre amarela, uma vez que observamos maiores níveis de anticorpos neutralizantes nos grupos vacinados com formulações contendo AbISCO.

Palavras-Chave: Febre Amarela, Subunidade, Plataforma Vegetal 